\title{
Penerapan Terapi Musik untuk Menurunkan Gejala Negatif pada Penderita Schizophrenia di Panti Sosial X
}

\author{
Jonas Danny Margan Kamardi ${ }^{1}$, Monty P. Satiadarma ${ }^{2}$, \\ dan Denrich Suryadi ${ }^{3}$ \\ ${ }^{1}$ Magister Psikologi, Universitas Tarumanagara \\ Email: jonas.dannymk@gmail.com \\ ${ }^{2}$ Magister Psikologi, Universitas Tarumanagara \\ Email: monty_satiadarma@yahoo.com \\ ${ }^{3}$ Magister Psikologi, Universitas Tarumanagara \\ Email: angiedenrich@yahoo.com
}

\begin{abstract}
As one of the social problems, schizophrenia has been noticed by theIndonesian government through Social Department. The constant increasing number of schizophrenics in Jakarta induces limitation of anti-psychotic drugs use in social institutions related to issues of financial support. Although the positive symptoms of the Schizophrenics can only be handled with pharmacotherapy, schizophrenic's well-being have the chance to be improved by reducing the negative symptoms. The use of creative therapies such as music therapy as a clinical intervention are potential to reduce negative symptoms in individual or group settings. Music therapy can be applied in a passive way, such as listening to music, and active way, which is singing and playing musical instruments. Positive and Negative Syndrome Scale (PANSS) was used to evaluate the negative symptoms of the participants. Systematic approach on learning to sing was implemented as the therapeutic approach on the participants. The sessions were conducted as many as 8 Sessions. The result indicates that music therapy by the way of singing can reduce the negative symptoms of the schizophrenic patients.
\end{abstract}

Keywords: schizophrenia, negative symptoms, music therapy, positive and negative syndrome scale (PANSS).

\section{PENDAHULUAN}

Makalah ini terdiri dari: Pendahuluan, skizofrenia adalah gangguan yang ditandai dengan kacaunya proses berpikir, persepsi, emosi, kontrol diri, motivasi, perilaku, dan fungsi interpersonal (Halgin \& Whitbourne, 2009). Gangguan skizofrenia menyebabkan terjadinya penurunan yang sangat drastis pada fungsi kognitif, yaitu atensi, memori, dan kecepatan memproses informasi. Hal ini menyebabkan individu dengan skizofrenia mengalami kesulitan dalam memisahkan informasi yang relevan dan yang tidak relevan dalam kehidupan sehari-hari (Nolen-Hoeksama, 2014). Skizofrenia juga dapat menyebabkan seseorang tidak dapat mengendalikan diri sehingga mendapat penolakan atau dikucilkan oleh lingkungannya dengan cara diisolasi (Halgin \& Whitbourne, 2009).

Gejala skizofrenia terbagi menjadi tiga kategori, yaitu gejala positif, gejala negatif, dan gejala disorganisasi. Gejala positif memiliki karakteristik adanya persepsi, pikiran, atau perilaku yang abnormal dan menonjol. Gejala positif dapat berupa delusi, halusinasi, disorganisasi bahasa, disorganisasi perilaku atau katatonik. Delusi menyebabkan seseorang memiliki keyakinan akan sesuatu yang tidak biasa atau tidak mungkin, misalnya meyakini bahwa dirinya adalah binatang liar. Halusinasi merupakan pengalaman persepsi yang tidak tepat terhadap realitas, misalnya mendengar suara-suara tanpa ada sumber suara. Halusinasi terjadi secara spontan dan menyebabkan penderitanya sulit untuk membedakan realitas (Halgin \& Whitbourne, 2009; Nolen-Hoeksama, 2014).

Gejala negatif pada individu dengan skizofrenia memiliki karakteristik defisit perilaku (Kring, Johnson, Davison, \& Neale, 2014). Gejala negatif dapat berupa hilangnya semangat atau motivasi terhadap aktivitas rutin, ketidakmampuan untuk berelasi sosial, hilangnya minat untuk 
terlibat dalam pengalaman menyenangkan, emosi datar atau tidak variatif, berkurangnya kuantitas bicara secara signitifikan (Kring et al., 2014; Dogra, Rana, Das, \& Avasthi, 2009). Individu dengan skizofrenia yang memiliki gejala disorganisasi bahasa akan sulit untuk melakukan proses kognitif seperti mengambil keputusan dan menggunakan logika (Halgin \& Whitbourne, 2009). Gejala disorganisasi bahasa juga menyebabkan penderitanya sulit untuk berinteraksi sosial karena sulit dalam menjaga alur percakapan, menggunakan bahasa yang tidak tepat, dan tidak teratur (Halgin \& Whitbourne, 2009). Gejala disorganisasi perilaku pada individu dengan skizofrenia dapat berupa gerakan-gerakan yang tidak bertujuan, gerakan berulang, gerakan kaku, atau ekspresi yang tidak tepat. Disorganisasi perilaku juga dapat berupa gangguan katatonik. Gangguan katatonik dapat dikenali dari gerakan yang sangat kaku seperti melakukan postur tubuh tertentu dalam jangka waktu yang sangat lama dan menjadi tidak responsif terhadap rangsang lingkungan (Halgin \& Whitbourne, 2009).

Penanganan skizofrenia secara khusus yang dilakukan di Indonesia, khususnya di Provinsi DKI Jakarta adalah melalui Dinas Sosial (Aprilia, 3 Oktober 2012). Berdasarkan data dari Dinas Sosial DKI Jakarta, jumlah penyandang psikotik (skizofrenia) mencapai 2.962 orang. Semuanya ditampung di panti sosial milik pemerintah provinsi DKI Jakarta yang idealnya hanya menampung 1.700 orang. Fakta ini menunjukkan bahwa daya tampung panti sosial telah melebihi kapasitas dan tidak sebanding dengan pertumbuhan penderita psikotik di DKI Jakarta (Windarto, 2015).

Salah satu penanganan gangguan skizofrenia yang utama adalah dengan terapi obat (Kring et al., 2014). Terapi obat dinilai sangat efektif untuk menurunkan gejala skizofrenia (Crawford et al., 2012). Namun, para penderita skizofrenia di Jakarta, khususnya di panti-panti sosial tidak lagi mendapatkan kunjungan psikiater yang memberikan resep obat (dalam Syarifah, 2015). Penderita skizofrenia diharuskan untuk datang ke layanan kesehatan atau puskesmas secara mandiri. Hal ini dinilai tidak mungkin untuk direalisasikan oleh pihak panti-panti sosial. Selain itu, jatah obat untuk individu dengan skizofrenia di DKI Jakarta juga telah dibatasi sejak Januari 2015 (dalam Syarifah, 2015).

Terbatasnya penggunaan obat menjadi alasan utama dari sulitnya menangani individu dengan skizofrenia. Gejala positif pada skizofrenia bersifat jangka panjang dan merupakan gangguan dalam proses berpikir yang cenderung sulit dirubah tanpa menggunakan pengobatan psikotropika (Mohammadi, et al., 2012). Keterbatasan obat dalam menangani gangguan skizofrenia menyebabkan perlu adanya terapi lain yang dapat menunjang fungsi mental dan sosial (Crawford et al., 2012). Terapi yang diberikan diharapkan dapat meningkatkan kesehatan mental dan membantu individu dengan skizofrenia untuk mengekspresikan diri mereka serta meningkatkan self-awareness (Crawford et al., 2012). Meskipun gejala positif pada individu dengan skizofrenia hanya dapat ditangani dengan menggunakan terapi obat, kesejahteraan mental dari individu dengan skizofrenia masih dapat ditingkatkan dengan cara menurunkan gejala negatif.

Terapi kreatif seperti terapi musik dapat menjadi alternatif yang memberikan dampak positif terhadap penderita penyakit mental (dalam Mohammadi, et al., 2012). Berbagai penelitian juga telah menyatakan bahwa gangguan skizofrenia dapat ditangani dengan menggunakan terapi musik (dalam Mohammadi, et al., 2012). Beberapa di antaranya adalah penelitian dari Mohammadi (et al., 2012) dan Talwar (et al., 2006) yang mengungkapkan bahwa terapi musik dinilai efektif untuk mengurangi gejala negatif pada individu dengan skizofrenia. 
Terapi musik adalah intervensi klinis yang menggunakan musik. Terapi musik merupakan salah satu intervensi psikososial yang dapat digunakan untuk menurunkan gejala skizofrenia serta meningkatkan interaksi sosial serta fungsi neuropsikologis (dalam Kwon, Gang, \& Oh, 2013). Terapi musik dapat mempengaruhi respon fisiologis, aktivitas sistem syaraf, sistem endokrin, dan sistem kardiovaskular. Terapi musik akhirnya akan menstabilkan mental dan fisik, meningkatkan emosi, fungsi kognitif, dan perilaku positif (dalam Kwon, Gang, \& Oh, 2013). Hal ini juga menjelaskan mengapa individu dengan skizofrenia cenderung melihat musik sebagai sesuatu yang menarik dan menenangkan (Kent, 2006).

Terapi musik dapat diterapkan dengan dua cara, yaitu pasif dan aktif. Terapi musik pasif diterapkan dengan cara mendengarkan musik, sedangkan terapi musik aktif adalah memainkan alat musik atau bernyanyi (dalam Kwon, Gang, \& Oh, 2013). Terapi musik aktif seperti bernyanyi memiliki dampak positif terhadap emosi dan menurunkan kecemasan. Terapi musik dalam bentuk memainkan alat musik juga dinilai sebagai aktivitas kompleks yang dapat melibatkan interaksi sosial dan proses mental (dalam MacDonald \& Wilson, 2014).

\section{Rumusan masalah}

Apakah terapi musik dapat digunakan untuk menurunkan gejala negatif pada individu dengan skizofrenia?

\section{Tujuan penelitian}

Penelitian ini bertujuan untuk mengetahui efektivitas terapi musik untuk menurunkan gejala negatif pada individu dengan skizofrenia. Secara teoretis, penelitian ini diharapkan dapat menjadi referensi tambahan dalam ilmu psikologi klinis dan metode intervensi yang efektif dalam menangani kasus klinis seperti skizofrenia. Secara praktis, penelitian ini diharapkan dapat meningkatkan kemampuan serta fungsi dari individu dengan skizofrenia. Penelitian ini juga dapat digunakan oleh keluarga dari individu dengan skizofrenia, tenaga medis, tenaga keperawatan, serta pekerja sosial dalam memahami terapi musik sebagai bagian dari intervensi psikologis yang dapat meningkatkan kualitas hidup serta fungsi dari penderitaskizofrenia.

\section{METODE PENELITIAN}

Partisipan Penelitian. Partisipan dalam penelitian ini adalah 3 individu dewasa awal dengan gangguan skizofrenia di panti X.Partisipan pertama memiliki gejala negatif afek tumpul dan menarik diri secara sosial yang menonjol. Partisipan pertama selalu terlihat menjaga jarak dengan orang lain dan menjauhi keramaian. Ia memperlihatkan ekspresi dan gestur tubuh yang kaku dalam kesehariannya, seperti selalu memegang tangannya sendiri, mengatupkan tangan, dan cenderung bungkuk. Partisipan kedua memiliki masalah dalam kemampuan verbal. Topik pembicaraan cenderung sangat dangkal dan tidak memiliki alur. Kosa kata yang digunakan sering kali sulit dimengerti dan terkadang menggunakan istilah yang hanya dimengerti oleh dirinya. Partisipan ketiga memiliki kesulitan dalam hal komunikasi karena rendahnya kemampuan verbal yang dimiliki. Partisipan ketiga juga selalu terlihat seperti orang yang bosan dan malas untuk melakukan sesuatu. Hal in dapat dilihat dari cara berjalannya yang lamban, suka tidur, dan tidak peduli dengan lingkungan sekitar.

\section{Desain penelitian}

Desain penelitian yang digunakan adalah one-group pretest-posttest design. Desain ini menggunakan pretest pada awal penelitian dan posttest setelah intervensi diberikan. Pretest dan posttest yang diberikan menggunakan alat ukur yang sama, yaitu Positive and Negative Syndrome Scale (PANSS) yang bersifat rating scale dan diisi oleh tiga orang rater (peneliti dan 
2 petugas dari panti X). Hasil setiap pengukuran pada setiap akhir sesi intervensi dievaluasi untuk mengetahui adanya perubahan dari kondisi partisipan.

\section{Lokasi penelitian}

Penelitian dilakukan di Panti Sosial X, Jakarta Barat. Peneliti memilih setting tersebut karena tempat yang bersangkutan memiliki calon partisipan yang memenuhi kriteria partisipan. Intervensi dilakukan di ruangan yang telah disediakan sebelumnya. Ruangan yang dipilih adalah ruangan yang dapat mendukung kenyamanan selama proses pengambilan data dan intervensi.

\section{Perlengkapan penelitian}

Perlengkapan penelitian yang digunakan adalah speaker, handphone, laptop, alat tulis, kertas A4, alat rekam, pedoman wawancara, informed consent, dan lembar alat ukur (PANSS). Pedoman wawancara yang digunakan mencakup preferensi musik, pengetahuan musik, dan pengalaman musik dari partisipan. Speaker digunakan agar musik dapat terdengar lebih jelas dan bersih sehingga memudahkan proses terapi musik. Handphone dan laptop digunakan untuk memudahkan peneliti dalam mengatur musik dan durasi dari terapi musik yang diterapkan. Lembar alat ukur digunakan oleh peneliti dan dua petugas panti yang telah dikonfirmasi sebelumnya. Kedua petugas panti $\mathrm{X}$ juga diberikan informasi tentang lembar alat ukur serta cara skoring.

\section{Pengukuran}

Alat ukur yang digunakan dalam penelitian ini adalah Positive and Negative Syndrome Scale (PANSS) for Schizophrenia dari Kay, Fiszbein, dan Opler (1987). Alat ukur ini memiliki 30 butir dengan definisi yang spesifik mengenai rentang penilaian (skala $1-7$ ). Ketujuh rentang penilaian tersebut merepresentasikan tingkat psikopatologi seseorang, (1) absent (tidak ada), (2) minimal, (3) mild (ringan), (4) moderate (sedang), (5) moderate severe (agak berat), (6) severe (berat), (7) extreme (sangat berat).

Gejala negatif yang diukur adalah blunted affect atau afek tumpul (kurangnya respon emosional ditandai dengan kurangnya ekspresi wajah, gelombang perasaan, dan gerak komunikatif), emotional withdrawal atau penarikan diri secara emosional (tidak adanya minat untuk terlibat dalam peristiwa penting dalam kehidupan), poor rapport atau raport buruk (kurangnya empati, kemauan untuk memulai percakapan, tertutup, tidak adanya keinginan untuk terlibat dengan orang lain ditandai dengan perilaku menarik diri dari orang lain dan kurangnya komunikasi), passive / apathetic social withdrawal atau penarikan diri dari situasi sosial (tidak adanya ketertarikan untuk terlibat dalam interaksi sosial karena perilaku yang pasif, apatis, avolition yang ditandai dengan tidak adanya rutinitas sehari-hari), difficulty in abstract thinking atau sulit untuk berpikir abstrak (ketidakmampuan untuk menggunakan kemampuan berpikir secara abstrak yang ditandai dengan sulitnya melakukan klasifikasi, generalisasi, dan berpikir konkrit dalam memecahkan masalah), lack of spontaneity and flow of conversation atau kurangnya spontanitas dan menjaga alur percakapan (berkurangnya kemampuan untuk menjaga alur percakapan yang ditandai dengan apatis, avolition, kurangnya interaksi secara verbal), stereotyped thinking atau pemikiran stereotipe (berkurangnya kelancaran spontanitas dan fleksibilitas dari berpikir ditandai dengan kakunya proses berpikir).

\section{Prosedur penelitian}

Penelitian didahului dengan mempersiapkan surat izin penelitian dari Magister Psikologi Universitas Tarumanagara. Setelah surat izin penelitian selesai diproses, peneliti memberikan surat tersebut kepada pihak administrasi di panti X. Sambil menunggu izin dari pihak panti X, peneliti kemudian mempersiapkan instrumen penelitian yang akan digunakan, seperti informed 
consent, speaker, laptop, alat tulis, kertas A4, dan lembar alat ukur. Peneliti juga mempersiapkan dua jenis informed consent, yaitu untuk calon partisipan dan petugas panti X. Informed consent tersebut kemudian diisi oleh calon partisipan dan pihak panti yang bersedia untuk membantu penelitian.

Peneliti kemudian mempersiapkan pedoman wawancara yang akan digunakan dalam penelitian. Pedoman wawancara digunakan untuk mengetahui latar belakang dan preferensi musik partisipan. Peneliti juga mempersiapkan lagu-lagu yang mungkin digunakan dalam proses terapi musik. Lagu-lagu tersebut dipilih berdasarkan hasil diskusi dengan dosen pembimbing dan petugas panti X. Lagu yang sudah dipilih kemudian di-download dan disimpan dalam laptop dan handphone untuk memudahkan proses terapi musik nantinya.

Setelah panti X memberi izin untuk melakukan penelitian, peneliti mulai membina rapport dengan petugas-petugas panti $\mathrm{X}$. Peneliti kemudian melakukan seleksi secara pribadi untuk menentukan petugas yang dinilai dapat membantu penelitian. Petugas yang dipilih kemudian mengisi informed consent dan diberikan informasi mengenai cara penilaian alat ukur PANSS. Petugas panti tersebut juga membantu peneliti dalam melakukan penilaian PANSS setiap kali sesi intervensi selesai dilakukan untuk memperoleh gambaran dampak dari terapi terhadap partisipan.

Peneliti kemudian meminta bantuan petugas panti $\mathrm{X}$ untuk memilih partisipan yang memiliki gangguan skizofrenia di panti $X$. Peneliti juga dibantu oleh petugas panti $X$ untuk mempersiapkan ruangan yang digunakan untuk proses wawancara dan intervensi. Ruangan yang dipilih adalah ruangan yang nyaman dan dapat meminimalisir suara dari luar yang dapat mengganggu proses wawancara dan intervensi. Peneliti bersama petugas panti $\mathrm{X}$ juga menyiapkan meja dan kursi yang dapat digunakan selama proses wawancara.

\section{Pelaksanaan intervensi}

Terapi musik dilakukan di ruangan yang telah dipersiapkan oleh peneliti dan petugas panti X. Terapi musik pada sesi awal dilakukan dengan cara memutarkan lagu yang telah disesuaikan dengan hasil assessment. Partisipan diberikan instruksi yang berbeda setiap kali terapi musik dilakukan, seperti mendengarkan, membuat ketukan dengan kaki, dan menepukkan tangan mengikuti ritme musik. Musik yang digunakan melibatkan elemen-elemen musik berupa ritme yang stabil (pulse dan pace yang konsisten), melodi yang mudah diprediksi, timbre yang sesuai (bersifat lembut untuk terapi musik pasif dan bersifat kuat pada terapi musik aktif), volume yang sesuai (agak lembut pada terapi musik pasif dan sedang hingga keras pada terapi musik aktif), harmoni dan bentuk yang sederhana (chord progression sederhana). Setiap sesi berlangsung selama 20 hingga 45 menit yang disesuaikan dengan kondisi partisipan. Pada setiap akhir sesi, peneliti dan dua orang rater (petugas panti X) menggunakan survei PANSS untuk mengevaluasi kondisi paritisipan.

\section{HASIL INTERVENSI}

Perubahan yang terjadi pada ketiga partisipan dalam penelitian ini dapat dilihat pada grafik yang ditampilkan pada gambar 1, 2, 3 dan 4. Skor yang ditampilkan pada alat ukur merupakan gambaran tingkat keparahan gejala negatif yang dimiliki oleh partisipan. Semakin tinggi skor yang diperoleh seseorang, maka semakin parah gejala negatifyang diderita. Semakin rendah skor seseorang, maka semakin ringan gejala negatif yang diderita. 

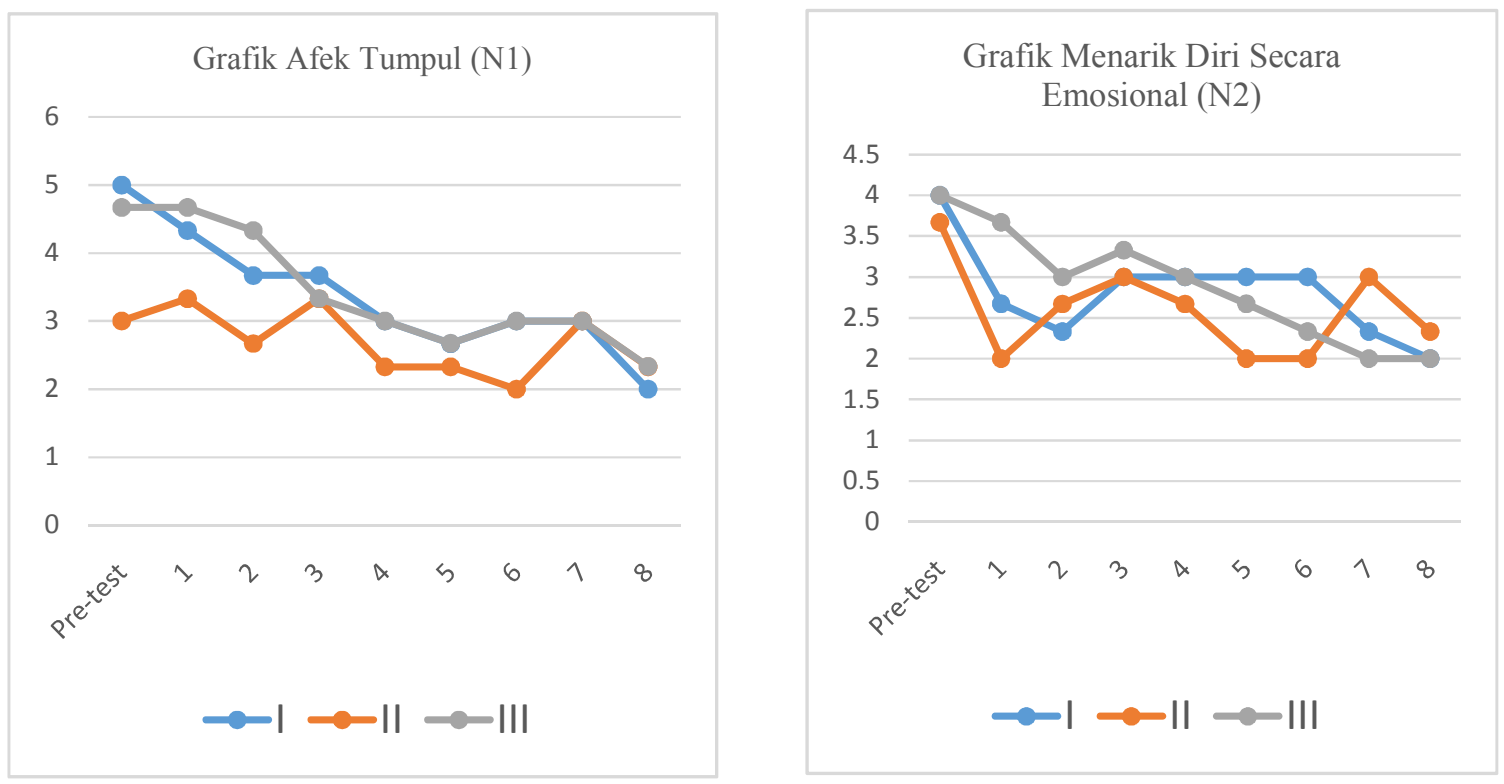

Gambar 1. Gambaran gejala negatif afek tumpul dan menarik diri secara emosional pada ketiga partisipan.
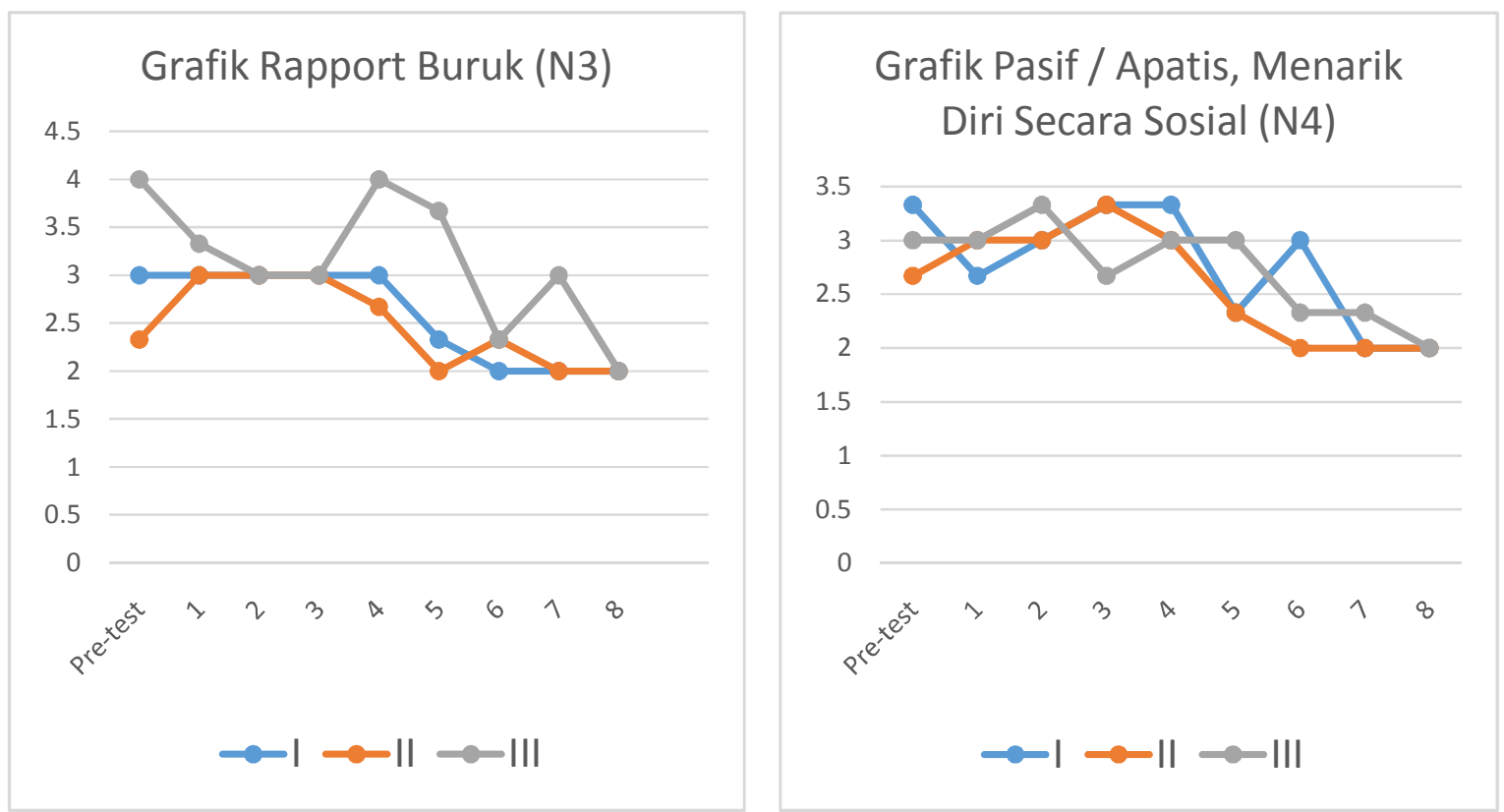

Gambar 2. Gambaran gejala negatif rapport buruk, pasif / apatis, menarik diri secara sosial pada ketiga partisipan. 

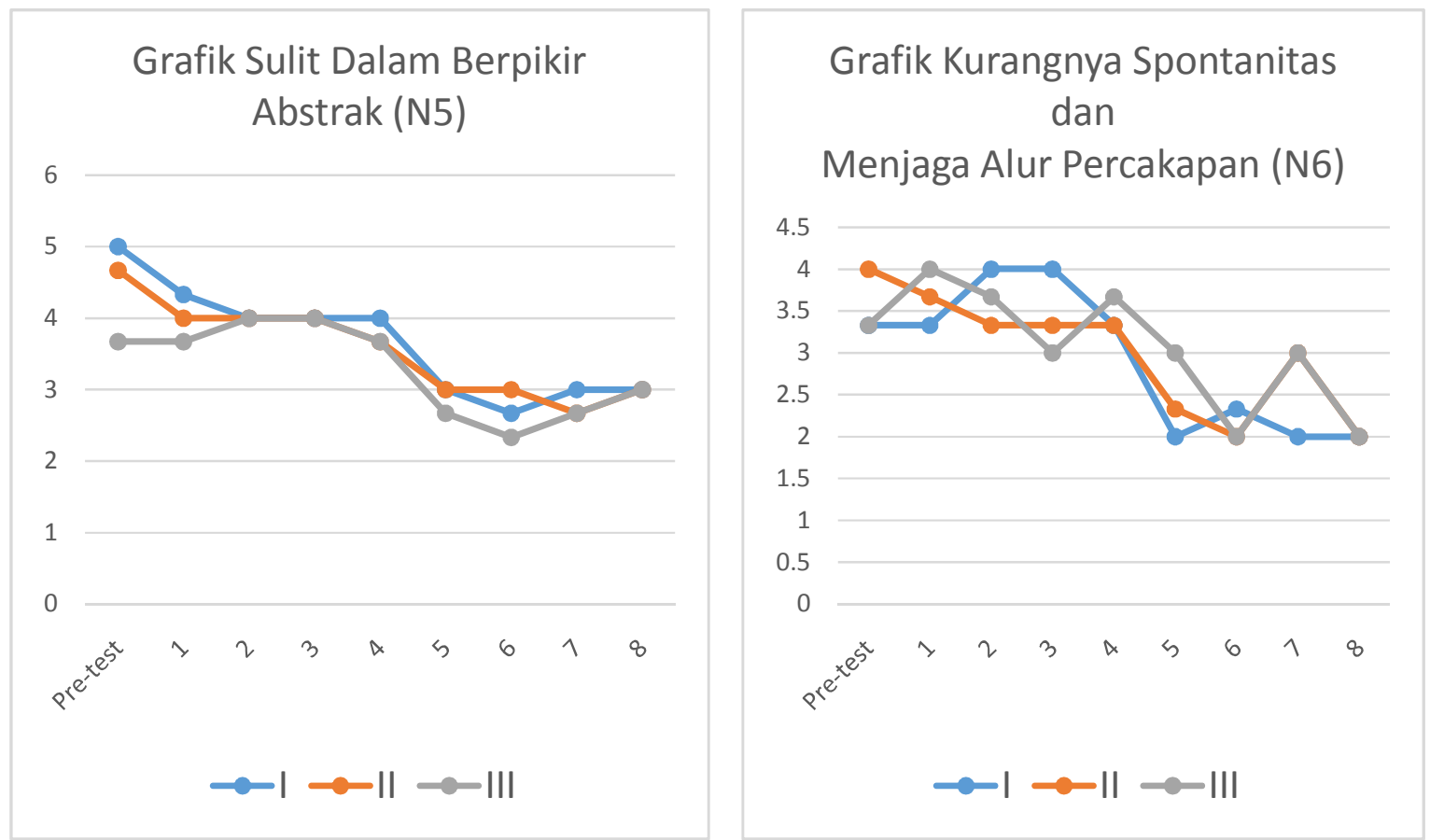

Gambar 3. Gambaran gejala sulit dalam berpikir abstrak, dan kurangnya spontanitas dan menjaga alur percakapan pada ketiga partisipan.

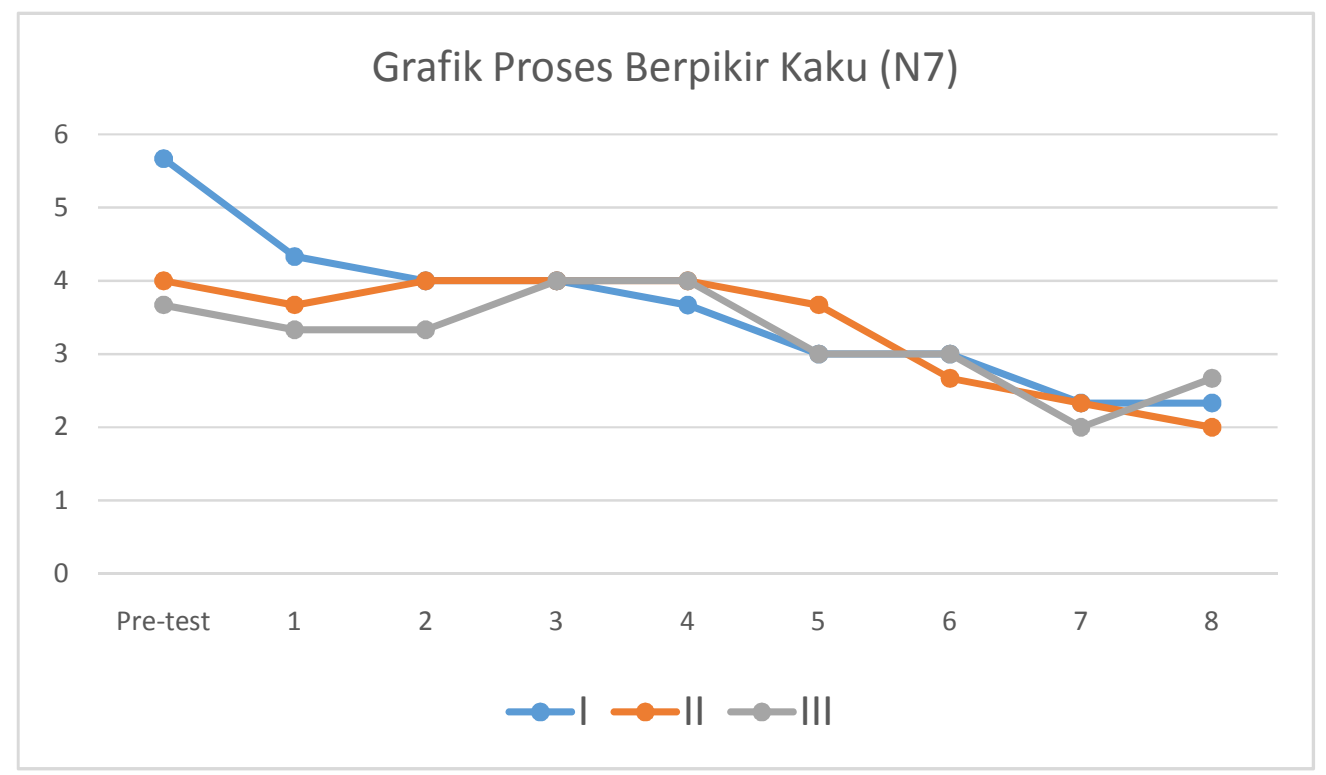

Gambar 4. Gambaran gejala negatif proses berpikir kaku pada ketiga partisipan. 


\section{SIMPULAN DAN SARAN \\ Simpulan}

Berdasarkan hasil pengukuran dan observasi yang dilakukan terhadap ketiga partisipan, dapat disimpulkan bahwa penerapan terapi musik terbukti efektif dalam menurunkan gejala negatif pada penderita skizofrenia. Perubahan dapat dilihat dari menurunnya skor yang diperoleh oleh ketiga partisipan pada alat ukur Positive and Negative Syndrome Scale (PANSS). Terapi musik terbukti dapat meningkatkan respon emosi, meningkatkan kemauan untuk berbaur dalam lingkungan sosial, dan meningkatkan kemampuan komunikasi seperti menjaga alur percakapan dan menyusun kata-kata.

\section{Saran lepada peneliti selanjutnya}

Peneliti menyarankan pada penelitian selanjutnya yang ingin meneliti tentang dampak dari terapi musik dalam setting klinis untuk memilih partisipan yang memiliki latar belakang dan minat tinggi terhadap musik. Partisipan yang memiliki latar belakang dan minat tinggi terhadap musik akan memudahkan peneliti dalam menerapkan terapi musik yang lebih bervariasi dan tidak menoton. Variasi dari terapi musik dapat dilihat dari luasnya pilihan lagu dan alat musik yang akan digunakan oleh partisipan.

Peneliti juga menyarankan agar penelitian mengenai terapi musik selanjutnya dapat berfokus pada kegiatan berkelompok. Dalam pelaksanaannya, peneliti sebaiknya juga memiliki kelompok pemusik dari luar kelompok partisipan yang mampu memainkan berbagai macam alat musik untuk memandu partisipan dalam kegiatan bermusik. Hal ini juga dapat menjadi motivasi bagi partisipan untuk terlibat dalam kegiatan bermusik.

Salah satu yang menonjol pada partisipan dalam penelitian ini adalah kurangnya kemampuan bermusik. Kurangnya kemampuan musik pada partisipan dalam penelitian ini dapat dilihat dari kesulitan-kesulitan yang dihadapi oleh partisipan selama sesi intervensi berlangsung, khususnya pada pitch dan ritme. Peneliti menyarankan kepada peneliti selanjutnya agar penelitian selanjutnya dapat menjelaskan dampak skizofrenia terhadap kemampuan musik seseorang.

\section{Saran kepada partisipan}

Setelah menjalani intervensi melalui pendekatan terapi musik, partisipan dalam penelitian ini telah mengalami penurunan gejala negatif. Partisipan disarankan untuk terus melatih teknik yang telah diajarkan secara mandiri, seperti teknik pernafasan. Selain itu, partisipan disarankan untuk terus meningkatkan kemampuan di bidang musik untuk dapat menyalurkan emosi dan menurunkan tingkat kejenuhan selama berada di panti. Partisipan sebaiknya aktif dalam kegiatan musik yang diadakan rutin dan berlatih bernyanyi sambil menggunakan teknik pernafasan yang telah diajarkan. Aktivitas bermusik juga diharapkan dapat menyalurkan energi yang dimiliki oleh partisipan dalam kegiatan yang bersifat menyenangkan.

\section{Saran kepada pihak panti sosial}

Petugas panti sebaiknya terus menjalin komunikasi dengan partisipan selama berada di panti. Petugas dapat memberikan instruksi kepada partisipan untuk membantu petugas dalam melakukan pekerjaan sehari-hari. Petugas juga sebaiknya dapat memfasilitasi kegiatan bermusik tidak hanya bagi partisipan, tetapi juga kepada semua Warga Binaan Sosial yang berada di Panti Sosial X. Kegiatan bermusik diharapkan dapat menjadi kegiatan yang lebih variatif seperti bernyanyi bersama dan belajar memainkan alat musik dalam kelompok. Pihak Panti Sosial X juga dapat merencanakan untuk menampilkan karya musik tertentu yang ditampilkan oleh Warga 
Binaan Sosial dalam acara tertentu. Hal ini diharapkan dapat menjadi motivasi dan menaikkan tingkat kesejahteraan Warga Binaan Sosial di Panti Sosial X.

\section{Ucapan terima kasih}

Penulis hendak menyampaikan puji dan syukur kepada Tuhan Yang Maha Esa atas berkat dan penyertaan-Nya berupa kesehatan serta kegigihan kepada penulis sehingga makalah yang berjudul "Penerapan Terapi Musik Untuk Menurunkan Gejala Negatif pada Penderita Schizophrenia di Panti Sosial X" dapat diselesaikan.

Penulis juga dapat melalui berbagai hal ini berkat bimbingan, saran, bantuan, dan doa dari berbagai pihak sehingga dapat mencapai bentuknya yang seperti sekarang ini. Penulis ingin mengucapkan terima kasih yang sebesar-besarnya kepada seluruh pengajar di Magister Psikologi Universitas Tarumanagara atas segala bimbingan serta ilmu yang telah diberikan kepada penulis yang sangat membantu proses pembuatan makalah ini. Penulis juga tidak lupa untuk mengucapkan terima kasih atas segala bantuan, masukan, kepercayaan, doa, dan dukungan dari Bapak Monty P. Satiadarma dan Ibu Denrich Suryadi yang telah diberikan kepada penulis selama proses dari awal hingga akhir.

Penulis juga berterima kasih kepada pihak yang telah ikut mendukung proses pengerjaan tesis ini, yaitu kepada Bapak Ruminto, Aks., MM. dan Bapak Ridwan dari pihak Panti Sosial yang bersangkutan. Penulis sangat berterima kasih atas kesempatan, kepercayaan, waktu, dan tempat yang telah diberikan kepada penulis untuk melakukan pengumpulan data serta pelaksanaan intervensi psikologis dari awal hingga penelitian ini berakhir. Dalam proses pengambilan data, penulis juga mengucapkan terima kasih yang sebesar-besarnya kepada Esa Katresna, Elang Sugianto, Zakky Mubaroq, dan seluruh pramu yang bekerja di Panti Sosial yang bersangkutan atas bantuan serta waktu yang telah diberikan sehingga proses pengambilan data dapat berlangsung dengan lancar dan tepat waktu.

Penelitian ini juga tidak akan selesai tanpa bantuan dari orang tua serta seluruh sahabat penulis. Oleh karena itu penulis juga mengucapkan terima kasih yang sebesar-besarnya serta doa kepada Annisa Prameswari Kesumaningrum, Ayu Eka Permatasari, dan Michael Gunawan. Peneliti juga mengucapkan terima kasih yang sebesar-besarnya kepada Berlian Julyeta, atas segala perhatian, cinta, dan dukungan yang diberikan saat penulis menemui berbagai kesulitan. Semoga kalian selalu diberkati dan dikaruniai rahmat serta penyertaan-Nya sehingga kalian senantiasa dilindungi oleh Tuhan Yang Maha Esa. Terima kasih juga kepada seluruh pihak dan temanteman dari penulis yang tidak dapat dituliskan satu per satu. Seluruh tulisan dalam makalah ini sepenuhnya menjadi tanggung jawab penulis.

\section{REFERENSI}

Aprilia, R. (3 Oktober, 2012). Sebanyak 27 panti sosial dikelola secara serius oleh dinas sosial. Viva.co.id. Diunduh dari: http://nasional.news.viva.co.id/news/read/356172-panti-sosialatasi-permasalahan-sosial

Arif, I. S. (2006). Skizofrenia: Memahami dinamika keluarga pasien. Bandung: PT. Refika Aditama.

Crawford, M. J., Killaspy, H., Barnes, T. R., Barrett, B., Byrford, S., Clayton, K., Dinsmore, J., Floyd, S., Hoadley, A., Johnson, T., Kalaitzaki, E., King, M., Leurent, B., Maratos, A., O’ Neill, F. A., Osborn, D., Patterson, S., Soteriou, T., Tyrer, P., dan Waller, D. (2012). Group art therapy as an adjunctive treatment for people with schizophrenia: a randomised controlled trial (MATISSE). Health Technology Assessment, 16 (8). 
Dogra, M., Rana, A., Das, K., dan Avasthi, A. (2009). An exploratory study on the effect of "activity scheduling" on the negative symptoms of patients with schizophrenia in psychiatry ward, nehru hospital, PGIMER, chandigarh. Nursing and Midwifery Research Journal, 5 (2), 107-115.

Halgin, R. P. dan Whitbourne, S. K. (2009). Abnormal psychology: Clinical perspective on psychological disorders ( $6^{\text {th }}$ ed.). New York: McGraw-Hill Companies, Inc.

Kent, D. (2006). The effect of music on the human body and mind (master's thesis). Diunduh dari: http://digitalcommons.liberty.edu/cgi/viewcontent.cgi?article=1162\& context=honors

Kring, A. M., Johnson, S. L., Davison, G. C., Neale, J. M. (2014). Abnomal psychology (12 ${ }^{\text {th }}$ ed.). UK: John Wiley \& Sons, Inc.

Kurniawan, M. (15 Oktober 2015). Jumlah penyandang psikotik di dki jakarta terus meningkat. Kompas.com. Diunduh dari: http://print.kompas.com/baca/2015/10/15/JumlahPenyandang-Psikotik-di-DKI-Jakarta-Terus-Me

Kwon, M., Gang, M., dan Oh, K. (2013). Effect of the group music therapy on brain wave, behavior, and cognitve function among patients with chronic schizophrenia. Asian Nursing Research, 7 (2013), 168-174.

MacDonald, R. A. R. dan Wilson, G. B. (2014). Musical improvisation and health: a review. Psychology of Well-Being: Theory, Research, and Practice, 4 (20).

Mohammadi, A. Z., Minhas, L. S., Haidari, M., dan Panah, F. M. (2012). A study of the effects of music therapy on negative and positive symptoms in schizophrenic patients. German Journal on Psychiatry, 15 (2), 56-62.

Nolen-Hoeksama, S. (2014). Abnormal psychology (6 $6^{\text {th }}$ ed.). New York: McGraw-Hill Education.

Rubin, A, Springer, D. W., dan Trawver, K. (2010). Psychosocial treatment of schizophrenia. New Jersey: John Wiley and Sons, Inc.

Schneck, D. J. dan Berger, D. S. (2006). The music effect. London: Jessica Kingsley Publisher.

Syarifah, F. (2015, 11 Maret). Obat dibatasi, pasien gangguan jiwa di jakarta mulai ngamuk. Liputan 6. Diunduh dari: http://health.liputan6.com/read/2189220/obat-dibatasi-pasiengangguan-jiwa-di-jakarta-mulai-ngamuk

Talwar, N., Crawford, M. J., Maratos, A., Nur, U., McDermott, O., dan Procter, S. (2006). Music therapy for in-patients with schizophrenia. British Journal of Psychiatry, 189, 405-409.

Weinberger, D. R \& Harrison, P. J. (2011). Schizophrenia (3 ${ }^{\text {rd }}$ ed.). UK: Blackwell Publishing Ltd.

Windarto (2015, 17 Desember). Masrokhan, kepala dinas sosial DKI Jakarta: terobosan buat penyandang psikotis. Diunduh dari: http://jakrev.com/megapolitan/masrokhan-kepaladinas-sosial-dki-jakarta-terobosan-buat-penyandang-psikotis/ 